\title{
How technology consultants assess the graphene and 3D printing hype
}

Carla Alvial Palavicino ${ }^{1} \&$ Kornelia Konrad ${ }^{2}$

1 ICSO-Universidad Diego Portales

2 University of Twente

\begin{abstract}
The hype-cycle is a phenomenon that is recurrently observed and spoken about in the context of emerging technologies. It is characterized by a wave of over-enthusiasm followed by a phase of disappointment, when promises are not met, and a later stage characterized by stabilization and maturity of the technology. A specific type of intermediary actor that has grown in relevance in recent years, known as technology consultants, plays an important role in assessing, deploying and making the "hype" visible within an innovation community. In this paper I study how technology consultants assess "the hype" for the case of two emerging technologies: graphene and 3D printing. We describe three different forms in which the hype is assessed: via technical expertise, as a social dynamic, and through social interaction. Each of these forms is a different way of arranging technologies, expectations, and actors, attributing different forms of agency to the innovation process. These three forms of "the hype" coexist as part of the activities of technology consultants and are used in different contexts. They allow consultants to maneuver and find a niche for their services in different contexts, while at the same time contributing to the co-production of an emergent field.
\end{abstract}

Keywords: graphene, sociology of expectations, hype, consultancy organizations.

\section{Introduction}

New and emerging technologies are often surrounded by promissory claims. These promises and expectations can be considered as a resource used by innovation actors in order to deal with uncertain futures (van Lente et al. 1998). Promises play an important role in the early stages of innovation processes, and can often lead to exaggerated claims and overpromising. The cycle of exaggerated promises followed by disappointment is known as the "hype-cycle," coined and introduced by the Gartner group (Fenn \& Raskino 2008). This consultancy organization provides an annual assessment of how various technologies are positioned in the hype-cycle: either at the peak, where overpromising is high; in the disappointment phase characterized by negative expectations; or in the plateau of productivity, when the technology has evolved and expectations have become more realistic. 
The hype cycle has spread across various technology fields, where technology actors speak about "the hype" and the "hype-cycle" to refer to the dynamics of technological expectations. Technology consultancies such as Gartner deploy assessments about hypes which affect the innovation activities, strategies and dynamics of actors in a technology field (Pollock \& Williams 2016; Pollock \& Williams 2010). This paper explores the role and practices of technology consultancy organizations in the assessment and articulation of technological hype cycles. These organizations seem to take both an enthusiastic and critical stance with respect to a technology, a selectively ambivalent attitude that is instrumental in positioning consultants' expertise. We are interested in understanding how these organizations assess and deploy "the hype" and how this affects the innovation community they are embedded in. This question will be addressed for two technologies that are currently described as "hyped": graphene and 3D printing.

Graphene is a carbon-based nano-material discovered in 2004, which has created a strong wave of enthusiasm in the scientific and technological world ever since (Shapira et al. 2012). The promises of graphene have prompted the initiation of a large, publically funded European project - the graphene Flagship -aimed at coordinating scientific and technological communities around a shared focal area (Peplow 2013). These developments have been accompanied by accusations of "hype" from actors ranging from scientists to consultancy organizations (Ghaffarzadeh 2013; Kozarsky 2015), who all expressed concern about the negative consequences that overpromising can have for the field.

This is also the case for 3D printing, a novel manufacturing technology that produces objects by adding layers in three dimensions instead of by subtracting material, and which involves a variety of industrial and consumer technologies. The consumer 3D printer, popularized by the media has fuelled the hype. Hailed as the enabler of a new industrial revolution, it is expected that $3 \mathrm{D}$ printing will radically redistribute manufacturing and innovation capabilities (Anderson 2012). Similarly, the hype has led actors to question the promises around 3D printing and its actual technological potential (Bass 2013).

In both cases, technology consultants have engaged both in the assessment and production of expectations about these technologies. Their future-oriented assessments range from estimation of potential markets and the benchmarking of products and companies, to evaluations of the state and plausibility of promises and expectations, including the position of technologies in the hype-cycle. The specific consultancies that participate in the production of knowledge about these fields vary between cases. Despite the differences in the technologies, the ways in which these organizations deploy "the hype" are similar. Against this backdrop, this paper addresses the following research question: How do technology consultants speak about and assess the idea of "the hype" and what is its performative role in an innovation field? To answer this question we discuss the processes and practices in which the hype is assessed, and their effects.

This paper is structured as follows: section 2 outlines an analytical framework to understand the role of expectations and associated practices in innovation. Section 3 introduces methods and approach. Section 4 presents an analysis of the processes through 
which graphene and $3 \mathrm{D}$ printing consultants deploy the hypes in graphene and $3 \mathrm{D}$ printing, and section 5 synthesizes and discusses the main findings.

\section{Framework : hype-cycles and performative expectations.}

Technological hypes are recurrent phenomena that can be observed for emergent technologies. Hype in general refers to a temporal and spatial evolution of expectations (including promises and concerns) characterized by a peak of high enthusiasm, followed by disappointment (van Lente et al. 2013). This form of characterizing the evolution of emergent technologies has become a shared belief among innovation actors, who speak about, predict and criticize hypes from their various perspectives (Rip 2006).

The Sociology of Expectations has extensively studied the role of expectations that constitute and lead to hypes in techno-scientific fields. Its main argument has been that these expectations are performative (Brown \& Michael 2003), i.e. they "do something" to the technological fields they refer to (van Lente et al. 1998). Saying that expectations are performative means that they take part in a process in which statements and the worlds they depict are co-produced. In this process, expectations serve different purposes, from legitimation to coordination, from guidance to sense-making (Borup et al. 2006; te Kulve et al. 2013; Swanson \& Ramiller 1997; Konrad et al. 2017). The production of expectations is enabled and embedded in specific socio-material practices, which have been called "anticipatory practices" (Anderson 2010; Alvial-Palavicino 2016). Through these practices the future is made present and actionable through specific materialities such as documents, prototypes, files, presentations, etc., which enable their circulation and performativity (Brown \& Michael, 2003). Intermediary organizations such as consultancies play an important role in the production and circulation of expectations through the production of graphs, scenarios, reports, prototypes, conferences, etc. (Kinsley 2012).

Pollock \& Williams (2010) have argued that in recent years there has been a proliferation of intermediary organizations, commonly known as technology consultancies that routinely produce future oriented expectations. They call them "promissory organizations" because their core business is the production and circulation of promises and expectations. They engage in specific practices through which they coordinate the activities of diverse innovation actors. In their extensive ethnography of the Gartner group, they have shown how this organization has multiple forms of influence, including particular practices such as the production of specific devices to spread out expectations such as graphs for technology benchmarking, rhetoric activities in relation to technology futures, and the production of tentative standards for new technologies (Pollock \& Williams 2016). These material forms of expectation enable the deployment and circulation of future-oriented concepts, such as "the hype cycle," which frame current developments and future possibilities. 
Similarly, Wilkie \& Michael (2009) have studied how the concept of "future user" shapes the type of futures that are made possible for an emerging technology. They have shown how the specific forms in which this concept is deployed enable and constrain the policy process in the articulation of $3 \mathrm{G}$ mobile technologies. Future users are portrayed as agents with the ability to shape a technology, but at the same time are presented as an entity that emerges from heterogeneous relations, practices, devices, people, information, and the technology itself. Thus, there are different definitions of future users that co-exist and that co-produce those very users. Law \& Mol (2002) have drawn attention to knowledge practices of definition and simplification, in which complex phenomena are translated into simple models. They argue that there are different ways of ordering and structuring things, and that these different simplifications co-exist with their own forms of organizing the world. Similarly, "future users" are co-constituted and performed together with $3 \mathrm{G}$ technologies, and the way in which they are defined produces different "future users" as assemblages of technologies, actors, practices, regulations, etc. This in turn is instrumental to the choices made in the policy process.

Thinking along those lines, it is interesting to reflect on the way in which consultants working on new and emerging technologies deploy, characterize and assess "the hype" when they speak about the future of a technology. For instance, the Gartner group positions a technology in the hype cycle based on a consensus assessment of many analysts about the state of expectations, the maturity of the technology, business applications, and industry. Each of these assessments is based on "proprietary" methodologies that can include econometric analysis, interviews, participation of events, etc. (Pollock \& Williams 2016). When "the hype-cycle" is referred to, it is presented as a simplified version of the dynamics that occur between expectations and technology development, a form of representing relations between the social and the technological, providing them with different forms of agency (Wilkie \& Michael 2009; Law \& Mol 2002).

There are multiple understandings of what is "hype" that are used by innovation actors such as consultants (Table 1). The Gartner group introduced "hype cycles" as an assessment tool of the market for a certain technology (Fenn \& Raskino 2008). More broadly, hype can be understood as the act of hyping: exaggerating or overpromising by technology actors, used strategically to gain support for a new technology (Ramiller 2006; Ruef \& Markard 2010). It can also be considered as a media phenomenon in its own right. It then denotes a phase of strong media attention that is followed by disappointment, which again might have longer-term negative effects for the perception of a technology by different groups of actors (Jensen 2012; Master \& Resnik 2013). Hypes can also be understood as "social bubbles" (Gisler et al. 2011; Borup et al. 2006), i.e. as a wave of strong social interactions in new ventures that lead to reinforcing feedback and extraordinary commitment of those involved in these ventures, connecting seemingly incompatible interests of scientific actors with those of the private sector.

Table 1. Different definitions of hype 
(1) Hype exaggeration as Hype or exaggeration is a practice by which technology actors more or less strategically raise and circulate exaggerated claims in order to promote a technology, in which the positive is highlighted while negative aspects are downplayed (Caulfield \& Condit 2012; Ramiller 2006; Rinaldi 2012; Ruef \& Markard 2010).

(2) Hype as Hype as a wave of media attention that is characterized by increased media very optimistic and exaggerated expectations, followed by attention more modest or negative expectations, which again create negative longer-term effects for the public trust in a given technology. These expectations are found mostly in media sources (Jensen 2012; Master \& Resnik 2013; Ruef \& Markard 2010; van Lente et al. 2013).

(3) Hype-cycle as The figure of the hype cycle refers to a particular way of an assessment tool assessing the status of an emerging technology given the expectations that are raised about it and its technological maturity. (Fenn \& Raskino 2008; Pollock \& Williams 2010).

(4) Hype as a folk A belief in the hype-cycle as a recurrent phenomenon for new theory technologies, which actors recognize and expect to occur, and use to draw conclusions without being an object of systematic research (Rip 2006; Brown \& Michael 2003).

(5) Hype as a social phenomenon
Hype as a wave of enthusiasm that mobilizes innovation actors to take risks that they otherwise would not take. It plays an important role in creating and sustaining protected spaces for new technologies (Gisler et al. 2011; Ruef \& Markard 2010; van Lente et al. 2013; Borup et al. 2006).

Social scientific approaches to understanding hypes are informed by some of these definitions, either describing strategic activities of actors in relation to hype (Ramiller 2006; Vasterman 2005; Nerlich 2013) or the discursive dynamics of expectations (Ruef \& Markard 2010; van Lente et al. 2013; Hyun Kim 2012; Bakker \& Budde 2012). In this paper, we focus on the forms in which hypes are assessed as part of the practices that technology consultants engage in when working with emergent technologies. Here, "the hype" is the result of expectations, actors, technologies, innovation activities and other elements that are assembled in various ways.

\section{Research Approach \& Methods}


This paper is based on two in-depth case studies in two emerging technology fields: graphene and 3D printing. For both cases, one of the authors followed and studied the activities of a set of promissory actors. The selection of actors was not predetermined from the beginning, but was the result of the evolving fieldwork: the consultancies referred here were encountered during each case study and appeared to be relevant in the field according to the interviews with other innovation actors, specifically entrepreneurs, investors and funding agencies.

The data collection included semi structured interviews with consultants in the graphene field (3), consultants in 3DP (2), as well as technology bloggers (2). Some of these actors were interviewed several times. The interviews were complemented with field notes from two 3D printing events (Euromold (2015, DE) and 3D Printing Event (2014, NL)) and three graphene events (Graphene 2013 (2013, ES), Graphene Stakeholders Association (2013, GSA) Meeting (2013, US) INC9 (2013, DE)), in which some of these consultancy organizations participated either as organizers, with a stand, or as speakers. This data was complemented with an analysis of the consultants' websites, blogs and social media (Twitter and LinkedIn).

In the empirical section, several types of actors are introduced. "Consultant" refers to a member of established organizations such as Gartner or other technology consultancies. "Independent consultant" refers to individuals who do not work officially in an established organization but offer their services as experts in a certain technology field independently. Lastly, "technology media" refers to actors who are involved in the production of information on diverse media (incl. social media, blogs, online videos, forums, etc.) about a particular technology, and who may or may not be associated to a consultancy organization. As shown, all these actors are interrelated in the process of sense-making of hypes.

The guiding heuristic for data analysis was to identify the instances and ways in which consultants assess and characterize hypes. This included not only consultants themselves, but also how other actors referred to consultants' hype knowledge. Data was coded to distinguish specific ways in which the hype was characterized and the type of anticipatory practices involved. Special attention was given to how these practices were enacted by various promissory actors and the type of relations that these practices entail. Lastly, the relation between different forms of deploying the hype and their performative effect in relation to the co-production of the broader technological field was evaluated.

\section{Consultants assessing hypes}

This section analyses through three vignettes the ways in which consultants assess and deploy the hype. A characteristic feature of new and emergent technologies is that there are accusations of hype during a phase of high optimism and attention (Ruef \& Markard 2010; Caulfield \& Condit 2012). Different actors (scientists, entrepreneurs, etc.) will claim that "technology $\mathrm{X}$ is hyped" (often referring to media framings) and strategically act upon this claim (Konrad et al. 2012; Budde et al. 2012). We argue that to position these claims, hypes also need to be assessed as such, and this is largely the work of promissory organizations. 


\subsection{Assessing hypes by technical expertise}

In some cases, a consultancy organization will make a diagnosis of expectations related to a technology and assess if these expectations are realistic or exaggerated, based on their technical expertise. This assessment is often presented as part of the results of a broader analysis of a specific technology, such as an analysis of its potential market, which is estimated through methods that include interviews, benchmarking, trend analysis and forecast. The release of a market report will often be accompanied by press releases that make reference to the hype status of a technology, which are used as part of the general information and promotional media that is circulated to promote reports.

This type of assessment can be observed in the way the Gartner group has been reporting about the 3D printing hype. The Gartner group yearly produces hype-cycle assessments for emerging technologies which feature "technologies that are the focus of attention because of particularly high levels of hype," or those that Gartner believes have the potential for "significant impact," enabling organizations to identify new business models (Gartner 2014). When a technology is introduced to this hype-cycle, it gains visibility and becomes a subject of discussion, and technology actors, including company CEOs, technology developers, scientists and policy makers, use this assessment in their own decision making processes (Steinert \& Leifer 2010).

Since 2010, the Gartner group has been mentioning 3D printing in this hype-cycle assessment (Gartner 2010). A feature of the hype-cycle as a methodology for benchmarking emerging technologies is that technologies are supposed to move through different stages of the hype over time: from the peak into the trough of disappointment, and then towards a plateau of productivity (Fenn \& Raskino 2008). From 2010 and until 2012, 3D printing was presented as a single technology located at the peak of the hype (Figure 1). In fact, media attention towards 3D printing has been such that it has not decreased but rather increased through the years (2010- 2014). This means that, in terms of the cycle, the technology has remained at the "peak of the hype" for about 4 years; yet, this does not mean that its expectations remained unchanged. The promises of 3D printing have shifted from general ideas and hopes about the potential of the technology, to a more structured discourse about the specific possibilities of the technology in different areas of application. In this process, innovation actors have made clear the different affordances of each technological path and its future possibilities (Potstada et al. 
2016).

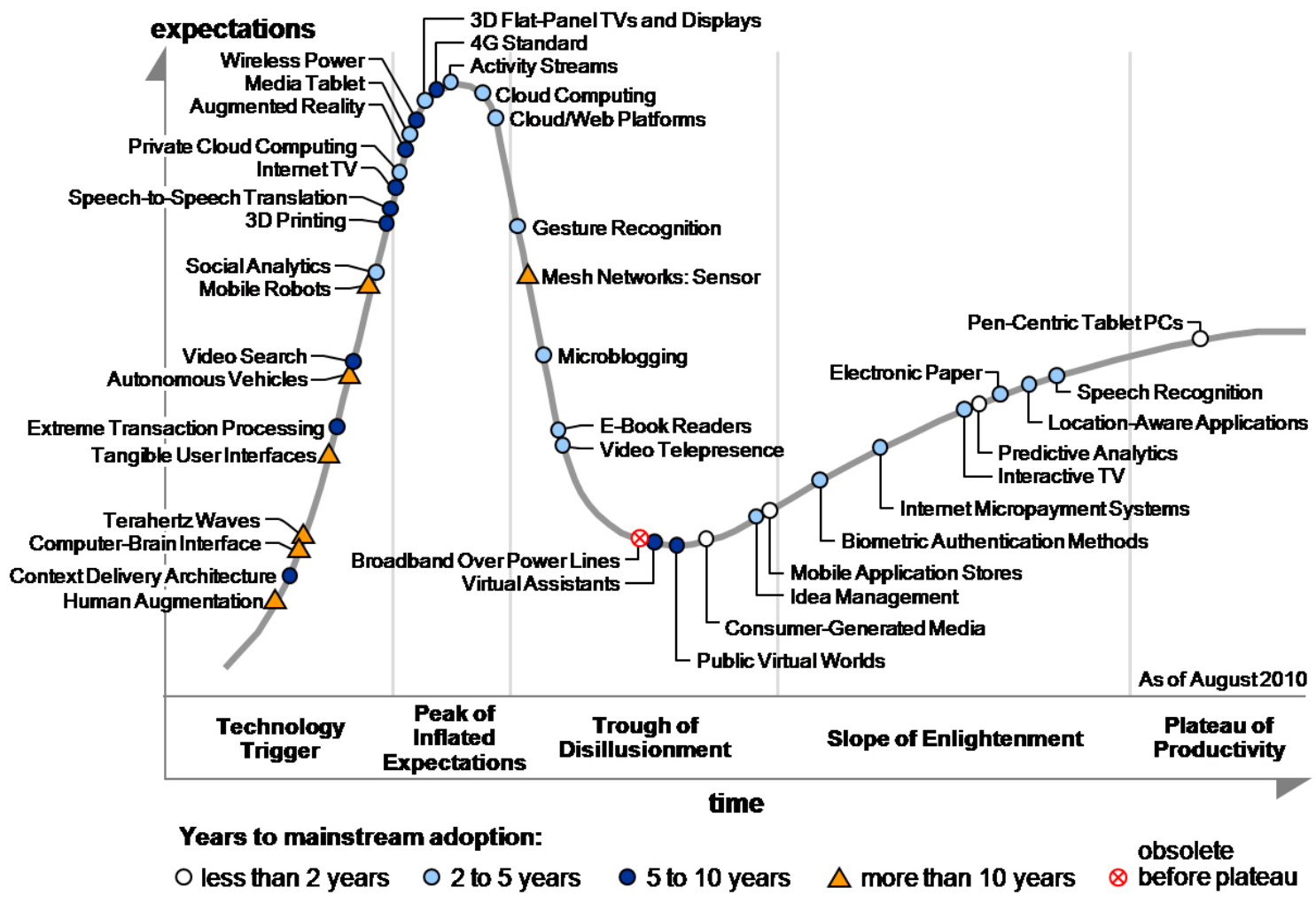

Figure 1. The Gartner's Hype Cycle for Emerging Technologies 2010. 3D printing as a single technology is located at the beginning of the hype, in the Technology Trigger phase. Nonmodified version, used with authorization of Gartner Inc. 


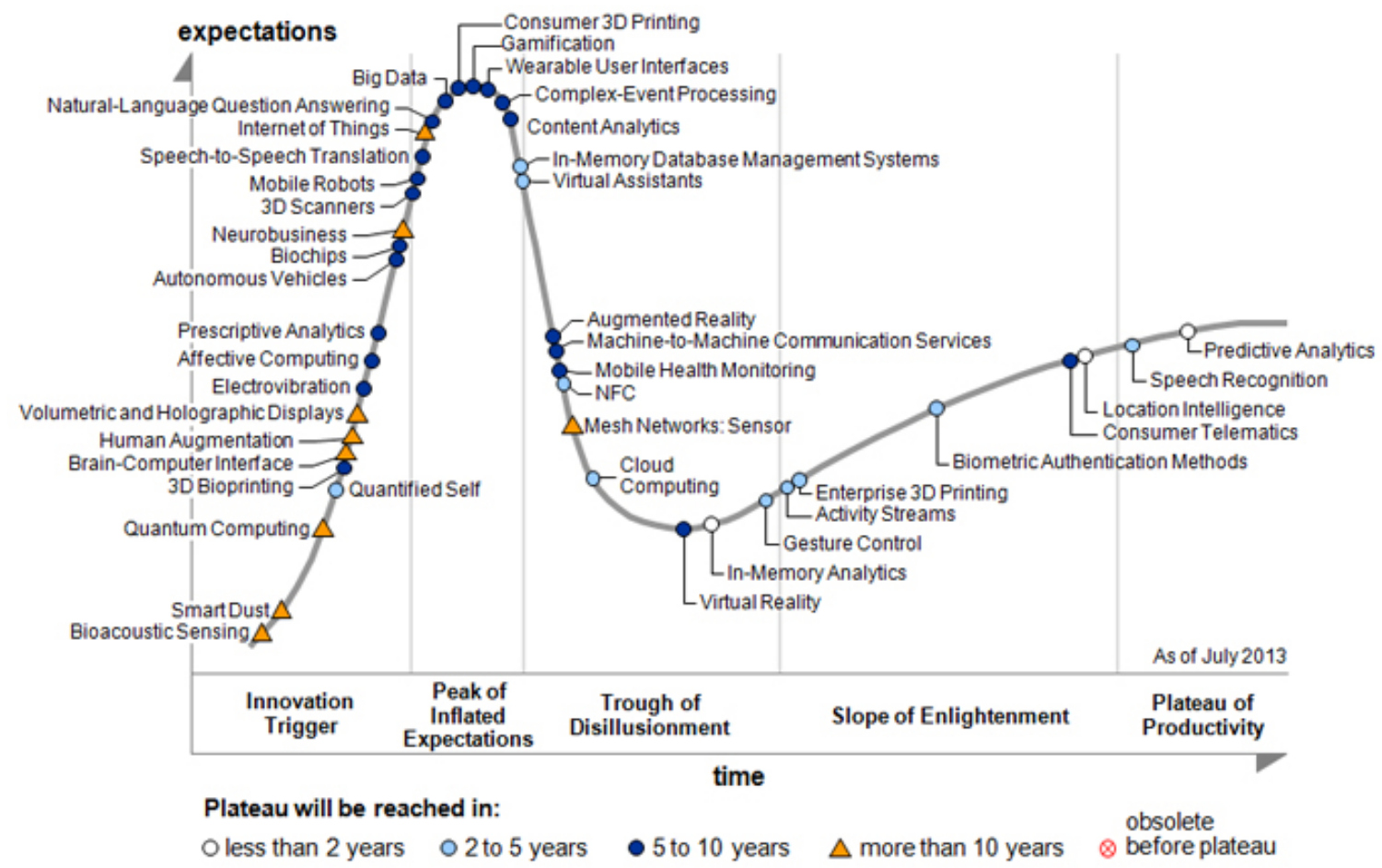

Figure 2. The Gartner's Hype Cycle for Emerging Technologies 2013. 3D printing is presented as four different technologies: 3D Bioprinting and 3D Scanners in the Innovation Trigger phase, Consumer 3D Printing at the peak of the hype and Enterprise 3D printing moving through the hype into the Slope of Enlightenment. Non-modified version, used with authorization of Gartner Inc.

In 2013 the Gartner group changed its assessment of 3D printing to speak of not one, but four different technologies, located at different points of the hype: 3D bioprinting, enterprise 3D printing, consumer 3D printing and 3D scanning (Figure 2). In this new assessment, consumer $3 \mathrm{D}$ printing still remained at the peak of the hype, while the other technologies were well spread over the cycle, either in the beginning or the end. As explained by an independent technology consultant who is not related to Gartner,

Gartner started to distinguish between consumer 3D printing and enterprise 3D printers last year (2013) which I think is really helpful. The big advances and developments, and the really meaningful stuff in the short term will come from these enterprise applications. Now regarding consumer 3D printers, it's really funny how consumer 3D printing sort of got stuck on the maximum point of hype, peak of inflated expectations. And you know this in itself creates a lot of probably very short-term opportunities. (...) So there is this kind of self-fulfilling prophecy of that hype which I think is really sort of short term. But if we look at the facts (it) has been around for the last, say, 4 to 5 years... which is kind of amazing. And it keeps repeating itself, it doesn't move, there is very little progress to be seen. (Interview 8, 3D printing, independent consultant, October 2014)

This new assessment provided in his opinion a frame that was closer to the observed dynamics of the field: enterprise 3D printing advanced in terms of concrete new business models and application areas, while consumer 3D printing remained at the peak of the 
hype without a clear "killer application." As he notes, keeping consumer 3D printing at the peak of the hype, while distinguishing it from other $3 \mathrm{D}$ printing technologies, is not only the reflection of strong, ongoing media and public attention, but also creates a "short-term self-fulfilling prophecy." In this new assessment of the hype, different technologies under the label of 3D printing are positioned against their general and specific promises, structuring what becomes the most "reasonable" paths of action. This means that a "window of opportunity" is created for the technology at the peak, which is characterized by high expectations that enable the emergence of new consumer 3D printing companies. This again reinforces and keeps the expectations about the technology high. That is to say, this self-fulfilling prophecy is co-produced and reproduced as the assembling of technologies and expectations in a reinforcing cycle. Being at the peak of the hype means that the particular arrangement of expectations, technologies and actors creates momentum for investment, and as this consultant notes, it becomes a self-reinforcing cycle.

This example illustrates how the hype cycle is not a just a method for prediction - its function is not to forecast technology dynamics. Instead, it is what Pollock \& Williams (2010) call a critical tool, a way of organizing the field. Based on their expertise, different technology analysts will assess the maturity of the technology, its market value and its business prospect. Such assessment is a combination of defined methodologies and the "expert view" of a field (ibid). In the case of 3D printing, Gartner employs a particular method of assembling expectations that opens or closes "windows of opportunity" for innovation actors.

\subsection{Assessing hypes by social dynamics}

A second way in which hypes are assessed is when presented as the result of social dynamics between innovation actors. This form of assessing hypes departs from the "technology maturity versus expectations" framework that represents the Gartner group's hype-cycle, to reflect on how different groups of actors engage in the production of expectations about a technology. These assessments are also circulated either as part of market reports, in blogs and press releases, or discussed in technology events. For graphene, these assessments deploy different understandings of the hype by two consultancies. The first one is the assessment provided by the consultancy IDTechEx that explains how the hype-cycle develops (Figure 3), and the second is the way in which the former nanotechnology consultancy Cientifica refers to what they call a nanomaterials hype cycle.

IDTechEx was founded in 1999 and is specialized in printed electronics and related areas. This company entered the graphene field in 2011 when they released a report in which they compared carbon nanotubes and graphene (Das 2011). This release was driven by the interest that clients of this company expressed in graphene (Interview 14 graphene, consultancy organization, July 2013). Their assessment, shown during a series of conference presentations, press releases, webinars and in their blog, diagnosed that graphene was moving just past the peak of the hype. A press release of 2012, which accompanied the release of a market report, included a figure of the graphene hype (Figure 3). This figure, which is referred to as the hype-cycle for graphene, represents the 
different stages of the hype in a way that is clearly informed by the framework provided by Gartner. The assessment provided at this point was that graphene was moving past the peak of the hype, based on indications such as companies going through a second or third round of funding, more realistic assessments of markets, and more "calibrated" expectations being circulated in the media (IDTechEx 2012).

While this framework is closely related to the Gartner hype-cycle, there is an important difference in the way it is used. What differs in IDTechEx's assessment is that they identify a spread of graphene activity, which means that graphene is not located at one point of the hype but at various points simultaneously, depending on the type of actor and technology they are referring to. This positioning is not solely based on a comparison between expectations and technical maturity, but also on the activities these companies are engaging in, particularly their relation to financial actors and development of markets. For example, it is implied that a second round of funding is a sign of maturity of the technology. The graphene hype-cycle is portrayed as the result of activities of diverse innovation actors, most importantly financial and technology actors, which change their relation over time as indicated by the activities they perform. This framework therefore draws attention to the way in which actors interact with others, rather than the technology itself. IDTechEx's hype assessment is explicit about the relations that are being developed between financial actors and emergent companies, and how this affects the development of a graphene market.

\section{[Insert Figure 3]}

Figure 3. The IDTechEx Graphene Hype Curve, as presented in their 2013's report. Reproduced with permission from IDTechEx Research

A different assessment of the graphene hype was provided by another UK based organization, Cientifica. Founded by Tim Harper, a charismatic figure in the nanotechnology world, the organization bears its founder's name in many of the activities it engages in. He has been involved regularly in promissory activities such as workshops, conferences, release of reports, and has served as consultant for a wide range of organizations, including the World Economic Forum.

In June 2013, this company released a report called "Investing in Graphene" that provided an assessment of the emergent graphene market (Cientifica 2013). This market report was in many ways similar to the other ones that were released at the same time by other consultancies: it included an assessment of the graphene market, and benchmarking of companies, applications, and future prospects. It was accompanied by a press release and a short summary of the report that included a historical overview of carbon materials and its implications for graphene. Most importantly, the report introduced a framework to understand what was referred to as "the nanomaterials hype-cycle." This cycle is characterized as a wave of overenthusiasm that moves through different actors groups. The main "selling point" of the report is a guide to "navigate" the cycle. The cycle is composed of five phases: (i) the academic hype, (ii) the corporate hype, (iii) the financial hype, (iv) the bubble burst and (v) the morass. Particularly interesting is his assessment of the peak of the hype, stage (iii) or the financial hype. 
"At the peak of the cycle with public awareness building, a range of investment gurus exchange traded funds and brokerages scramble to get a slice of the pie. Technology experts and investors emerge from every nook and cranny, and every week at a conference someone predicts an even bigger market. A few companies (and their investors) get rich from well-timed IPOs. Companies engage in a production capacity arms race in order to address a still non-existent market." (Cientifica 2013)

This description is in line with earlier assessments, and also with IDTechEx assessment, that show that hypes and financial markets are intimately related (Wüstenhagen et al. 2009; Gisler et al. 2011). Particularly because during times of hype there is more availability of investor funds and venture capital that make it easier for newcomers to enter a field (Interview 8 graphene, company CEO, December 2013 and Interview 27 graphene, company CEO, December 2013). As if it were a self-fulfilling prophecy, shortly after the release of this report Cientifica announced that it would transform its operations from a consultancy organization to an investment one. In the second half of 2013, Cientifica PLC went public into the AIM market of the London Stock Exchange. ${ }^{1}$ The area of investment of this renewed Cientifica was mainly graphene.

This was not the only company that went public under similar conditions at the end of 2013: at least two other UK based companies, producers of graphene, did the same. The overall response of investors was very positive, with the IPO being even "oversubscribed." The hype went, however, far beyond the mere oversubscription. At the very end of 2013 the financial authority of the UK (FCA 2013) warned that investments in graphene were dubious due to the lack of standards and regulations in graphene, and it could not confirm the quality of products. As the FCA put it, "we are concerned about investments involving a man-made material called graphene. Find out more and how to protect yourself." This particular incident coincided with the earlier assessment of the hype provided by Cientifica: the financial hype, in which financial actors take advantage of the expectations about a technology and make strategic investments.

This second form of assessing and deploying the hype gives a structure to the way in which various types of actors become engaged in graphene and shape the graphene hype. It defines the way in which actors raise expectations. In that respect, the hype becomes the result of the alignment of actors in relation to expectations and to each other. This is clear from the way Cientifica assesses and materially circulates the peak of the hype.

These two forms of assessing the hype represent it as a social dynamic. In that sense, the hype is not portrayed as the juxtaposition of a technology versus its promises, but rather as the way in which innovation actors relate to each other. This representation of the hype assembles actors and the particular practices they engage in, related to expectations, in an orchestrated manner, in which a scientific discovery is followed by the development of technological products, investment, and the public uptake of these technologies. It

1 Cientifica did not technically engage in an IPO but took over an existing company in the AIM market, namely Avia Health Informatics. 
defines the kinds of relations that can take place between different kinds of actors and how they are expected to behave. However, the way these "social" assessments are presented differs. IDTechEx's interpretation of the hype takes distance from the dynamics it represents, appearing as objective, based on "facts" and as a form of abstract knowledge that can be used by any other actor in the field (Suddaby \& Greenwood 2001). In their representation of the hype, there are no particularities of the technology itself, but instead a given structure under which companies, investors and technology developers and their expectations relate to each other.

In contrast, the hype assessment provided by Cientifica puts this organization at the core of the hype itself, largely based on their experience on nanotechnology. It does not intend to be generalizable to every technology; instead, showing the particularities of nanomaterials, it aims to position Cientifica as relevant experts in the field, who can be trusted when it comes to nanomaterials investments. There is a difference in the way "investment" is treated in these frameworks. For IDTechEx, a first and second round of investments are signs of positive expectations and maturity; in contrast, for Cientifica, a round of investment is inevitably accompanied by a "bubble-like" effect, in which expectations are not met. These different assessments also reflect the way each consultancy positions itself among other actors in the field: IDTechEx presents itself as an objective observer of the dynamics, while Cientifica is explicit about their ability to shape the field itself. These are two ways in which consultancies define their roles in a field: either based on their expertise and ability to technically assess a particular topic (and this is why they need frameworks) or based on their experiential knowledge. These actors "know hypes" because they have experienced it a number of times (Interview 10 graphene, technology blogger, June 2013). Thus, they have the experience to guide other innovation actors through the hype in a way in which they can avoid its downsides and negative effects.

\subsection{Assessing hypes as a form of social interaction}

There is a third form of assessing hypes in which the hype becomes a space in which to collectively frame expectations about a technology. This third form of assessing the hype is constituted by the collective disassembling and reassembling of expectations, frameworks, and assumptions about a technology, which happens through the interaction of consultants with other innovation actors during particular events. In this case, the notion of hype is presented as related to the plausibility of the expectations that circulate around a technology in a certain time. The accuracy of expectations can only be fully assessed in retrospect, thus whatever is assessed as a plausible expectation must be understood under a set of criteria that lie outside its correspondence to actual facts.

As Pollock \& Williams (2015) have argued, the site of predictions has moved from the text (the literary) to interactive events, where predictions that promissory organizations make are socially checked. In these events, assessing the robustness and credibility of expectations is a largely interactional process in which predictions are socially evaluated. It is particularly in the interactive setting offered by technology conferences that a meaningful exchange between innovation actors and consultants can take place. 
These technology events take place both for the graphene and 3D printing fields, and are often run by specialized organizations, which I refer as technology media. Consultancies also organize events in specific areas: IDTechEx co-locates an event called Graphene LIVE! with their Printed Electronics show, and they also organize an event about 3D printing. During the year many of these events will take place around the world, and for technology companies it is important to be present either with a stand or as speaker in as many events as possible (as seen in some of the events attended such as GSA meeting 2013 and Euromold 2014).

In these events, the hype is assessed and deployed collectively; expectations are discussed, analysed and assessed in a process led by consultants. This was the case of a graphene conference in 2013. In this conference, a consultant from IDTechEx was invited to speak about graphene and its future. He diagnosed a hype about graphene, attributed to a "market confusion," which derives from the fact that "graphene" refers to a multiplicity of materials of different qualities and fabrication methods, and which can be used for very different applications. As he explains,

"We all know that graphene is a great material, it is probably the best material ever created, but when you look at it from the market point there is no one type of graphene, there are many types, and each represents a different market."

(IDTechEx consultant, Graphene 2013 Conference)

By introducing this distinction, he offers a different way of thinking about the graphene hype: it is not only the result of exaggerated expectations, but also the result of a lack of coherent narrative about what the field is actually about, its interconnections, and the product structure. He also offers a new way of thinking about what graphene actually is: instead of a singular graphene, there are multiple "graphenes," different materials with distinctive properties. Each of these different "graphenes" addresses a different product space (i.e. they refer to different expectations), so different strategies need to be developed. The consultant engages in a type of benchmarking exercise where he compares the advantages offered by each form of graphene against the materials it intends to replace for different applications. He shows that the lack of a coherent narrative of what graphene can do is counterproductive to setting up a market. In this fragmented space, coordination among different market is hard to achieve and there is space for misunderstanding. Coordination is necessary to produce a real market for graphene, which would essentially be enabled by a game-changing or "killer" application ${ }^{2}$ that takes graphene into the mainstream.

The audience of this talk received this critical claim with some surprise. However, this did not undermine the legitimacy of these claims or the knowledge it entails. Instead, it gave the analyst authority and credibility among other innovation actors. This is a

2 A killer application is a product that has such highly desirable properties that it generates high profit in a short amount of time. It also helps to promote the underlying technology, helping to provide disruptive technologies with wide societal acceptance (Becker 2009). 
common trait of the consultants in graphene and 3D printing: they are both critical and optimistic. They tend to present themselves as critical observers of the dynamics of the field who provide frameworks to understand, evaluate and act in relation to the developments in each field. By doing so, they generate legitimacy for their hype-cycle assessments, for the field, and, ultimately, for themselves.

A similar instance of problematizing expectations takes place in $3 \mathrm{D}$ printing events. In a conference organized by the technology media company TCTShow in 2014, there was a set of presentations called "Debugging 3D printing." In these talks the presenter would ask the audience to distinguish truth from exaggeration in the field, by providing the means to assess claims, promises and predictions. One of the speakers performed a gamelike exercise in which the audience had to decide if a certain statement on 3D printing was plausible or not, by lacing it in one of two rows, labelled "ridiculous" or "plausible" (TCT+Personalize 2013). The speaker introduced this game by saying that there are a lot of myths and misinformation about 3D printing, for which he blamed the media. Instead, he noted that he was committed to finding those expectations that are real, and looked for legitimation in the audience, especially among those "who work for the industry." The first myth he "debugs" is: can you 3D print anything?

I am gonna start with "you can 3D print anything." Common misconception; 3D printing has a lot of rules and regulations to it, and you can't... on a lot of machines you can't print certain complexities. One of the tricks of 3D printing is that you can print any shape but actually on some of the FDA machines you can't print overhangs unless they have the support material or you built a support structure into it. Anyone got an opinion on this?... this is all completely unfair! I need someone at least! ... that it's ridiculous! can you 3D print anything? No, OK. So, a vote on this? Can you 3D print anything? This way? Ridiculous, plausible, ridiculous, plausible... Hands up for ridiculous? Hands up for plausible? Yes! One nailed (TCT+Personalize 2013)

By engaging in this myth-busting exercise, he not only mobilizes technical knowledge to argue against the "myth," but also puts into question his own assumptions and looks for support from the audience, who has the tacit and experiential expertise to assess these predictions. To do so, he raises these and other propositions that circulate in the media about $3 \mathrm{D}$ printing (3D printing will bring jobs back to the West, $3 \mathrm{D}$ printing is good for the environment, etc.) and presents his own way of thinking about it. He allows the audience to respond to these propositions, explaining why they think a prediction is accurate or not, and to decide whether a prediction is ridiculous or plausible. By means of this exercise, he tries to show that the frames of thinking about technology that lead to hype are simplifications of complex problems. For example, as he goes on to discuss the question: is $3 \mathrm{D}$ printing cheap?

The discussion is opened to the floor, which, based on their own experiences with 3D printing, audience members present their different perspectives, showing that $3 \mathrm{D}$ printing can be cheap in certain cases. For this reason, the speaker decides to divide his slide in two and put half of the statement in "ridiculous" and half in "plausible". The 
process is not just a consultant showing his expertise, but a form of collective knowledge production. Actors themselves, including consultants, "learn" from the experience of other technology actors and undergo a transformation. In fact, for technology consultants it does not seem to be delegitimizing to be proven wrong, or to change their opinion about a subject (Pollock \& Williams 2015; Reeves 2014). In this sense, their knowledge about a field is accepted as highly contingent.

This third form of assessing and representing hypes is its foremost collective. It involves the collective disassembling and assembling of the expectations that make "the hype" by actors who are themselves participants in the hype. This is possible in collective practices such as technology events, in which an informal dialogue emerges between consultants and other innovation actors. Expectations are discussed, opened up, reframed, and not just proven wrong. Re-framing expectations and the way of thinking about the field creates space for multiple interpretations and predictions: graphene will be different depending on the type of material we are speaking about; 3D printing can or cannot be cheap, depending on how an application is benchmarked against its competitors.

By reframing generalized expectations into complex narratives, multiple possible paths become evident. One might ask what the use of such rephrasing is. The way in which consultancies make profit is mostly by providing one-to-one services to companies or investors (interview 14, consultant, July 2013). By opening up such multiple opportunities they expand the market; at the same time, they make expectation look less "unrealistic" and more "imprecise," triggering the activities of other innovation actors to explore these multiple possibilities.

\section{Discussion: The materiality of hypes}

This paper discusses three forms of assessing, deploying and representing "the hype" by technology consultants, which are different forms of representing how expectations influence the development of technologies. These three forms are technical expertise, social dynamic and social interaction, and they refer to characteristic ways in which technology consultants define, assess and make hype-related claims. These are all produced by the same technology consultants, but deployed in different contexts and different practices.

An assessment based on technical expertise represents hypes as a relation between technologies and expectations, in which an early stage technology needs maturity to achieve its promises. Here, actors are absent from the production of a hype. The potential of the technology is there, and the peak of the hype appears as an opportunity. This representation of the hype responds to the technical expertise consultants have about a technology, taking some distance from the (social) dynamics of the field itself. It relies on a specific device: the Gartner hype cycle curve, in which technologies are positioned and benchmarked against, based on market situation, technology maturity, IP and other variables.

An assessment of the hype as a social dynamic represents it as the result of relations between different types of innovation actors that change over time. In this way, what actors can expect from others is orchestrated by the frame given in reports, social media 
and technology events. This assessment is presented as the result of the experiential knowledge consultants have in the field, i.e. actors who know about this early stage dynamic because they have experienced it a number of times. In this second form of assessment, the expertise of consultants is predicated on the position they have among other innovation actors, as an abstraction of the social network in which they operate (Evans 2007).

Lastly, an assessment as a form of social interaction interprets the hype as a space in which to question the expectations about a technology, such that the underlying conceptual assumptions are collectively opened up and reframed. This last form of assessment takes place in technology events, which are the "site of prediction" of technology consultants. As has been argued (Pollock \& Williams 2015), the function of these consultants is not primarily to make accurate predictions. Rather, they provide a framing that allows other technology actors to speak a common language that guides their collective action. It does not matter if the predictions made by consultants do not materialize, or if they change opinions over time. By collectively opening up "the hype," and reconstructing what counts as plausible expectations, consultants are also able to position their own expectations and, most importantly, expertise, in the field.

We have shown that the same organizations produce different assessments of the hype, different forms of distributing agency among technologies, expectations and actors. A technical assessment of the hype understands the innovation process as the result of technology itself; a social dynamic assessment gives a limited agency to actors, setting the boundaries under which they can operate. A social interaction form of hype gives higher agency to actors in the shaping of expectations, keeping the future open to multiple paths and possibilities. Each of these assessments embeds distinct understandings of how the future will come about, either as a linear development or as multiple options.

There are two consequences to these forms of assessment. The first one is that each of them introduces different performativities of "the hype," because it structures the relations in multiple ways that co-exist. The second one is that, even for consultants, there is no singular theory of hype but different forms of deploying the hype, depending on the public, context and purpose. From the definitions of hype introduced in section 2, consultants move between (3) hype as an assessment tool which shows their technical expertise, (5) hype as a social phenomenon, in which different actors come together, and (4) hype as a folk theory, i.e. a non-expert way of speaking about expectations and technology futures. It is this hybrid character of hype that could help to understand how these consultancies operate. We have started with the apparent dilemma: consultants are at the same time optimistic and critical about technology fields. Also, we have shown that they do not constitute a coherent collective that provides clear-cut answers about technology futures, but instead provide frameworks through which other actors think about and act upon technology. In short, the work of consultants assessing the hype consists in creating assemblages of technologies, expectations, actors and practices. In doing so, these promissory actors create a niche for themselves and sustain their activities and continuity in a field. 
We have shown that the relations between actors, technologies and expectations that are deployed in each assessment of the hype differ, as does the agency that is given to each of them. Thus, the hype itself is co-produced with the models, theories and forms of knowledge about it. The forms of assessment of the hype provided by these consultants are used as a means to also shape their own role in these fields. They provide specific images to situations that are experienced by the community of innovation actors as a whole. Consultants move through the hype by enacting it in a variety of forms and contexts, and they also provide means for other innovation actors to shape the spaces in which they can move. These images and discourses are ways of understanding future promises and visions that structure methods of strategic action and intervention. In this respect, they also fulfil a function of anticipatory coordination in the early stages of technology development.

\section{Funding statement and declaration of conflicting interest}

This research was funded by the program NanoNextNL 1C Risk \& Technology Assessment. The authors declare to not have any conflict of interest.

\section{References}

Alvial-Palavicino, C., 2016. The Future as Practice. A Framework to Understand Anticipation in Science and Technology. TECNOSCIENZA: Italian Journal of Science E Technology Studies, 6(2), pp.135-172.

Anderson, B., 2010. Preemption, precaution, preparedness: Anticipatory action and future geographies. Progress in Human Geography, 34(6), pp.777-798.

Anderson, C., 2012. Makers: the new industrial revolution, Random House.

Bakker, S. \& Budde, B., 2012. Technological hype and disappointment: lessons from the hydrogen and fuel cell case. Technology Analysis \& Strategic Management, 24(6), pp.549-563.

Bass, C., 2013. An Insider's view of the myths and thruths of the 3D printing "phenomenon." Wired.

Becker, H., 2009. Hype, hope and hubris: the quest for the killer application in microfluidics. Lab on a Chip, 9(15), pp.2119-2122. 
Borup, M. et al., 2006. The Sociology of Expectations in Science and Technology. Technology Analysis and Strategic Management, 18, pp.285-298.

Brown, N. \& Michael, M., 2003. A Sociology of Expectations: Retrospecting Prospects and Prospecting Retrospects. Technology Analysis \& Strategic Management, 15(1), pp.4-18.

Budde, B., Alkemade, F. \& Weber, K.M., 2012. Expectations as a key to understanding actor strategies in the field of fuel cell and hydrogen vehicles. Technological Forecasting and Social Change, 79(6), pp.1072-1083.

Caulfield, T. \& Condit, C., 2012. Science and the sources of hype. Public Health Genomics, 15(3-4), pp.209-217.

Cientifica, 2013. Investing in Graphene. Available at: http://www.cientifica.com/wpcontent/uploads/downloads/2013/07/Investing-in-Graphene.pdf.

Das, R., 2011. Carbon Nanotubes (CNT) for Electronics \& Electrics 2013-2023: Forecasts, Applications, Technologies Read more at: http://www.idtechex.com/research/reports/carbon-nanotubes-cnt-for-electronics-andelectrics-2013-2023-forecasts-applications-technologies-000,

Evans, R., 2007. Social networks and private spaces in economic forecasting. Studies in History and Philosophy of Science Part A, 38(4), pp.686-697.

FCA, 2013. Graphene Investment Schemes. Available at: https://www.fca.org.uk/consumers/graphene-investment-schemes [Accessed January 1, 2013].

Fenn, J. \& Raskino, M., 2008. Mastering the hype cycle: how to choose the right innovation at the right time, Boston, MA: Harvard Business Press.

Gartner, 2010. Gartner's 2010 Hype Cycle Special Report Evaluates Maturity of 1,800 
Technologies. Gartner. Available at: http://www.gartner.com/newsroom/id/1447613 [Accessed May 1, 2015].

Gartner, 2014. Gartner's 2014 Hype Cycle for Emerging Technologies Maps the Journey to Digital Business. Available at: http://www.gartner.com/newsroom/id/2819918 [Accessed June 1, 2015].

Ghaffarzadeh, K., 2013. Graphene - what next after the hype? IDTechEx.com. Available at: http://www.idtechex.com/research/articles/graphene-what-next-after-the-hype00005454.asp [Accessed May 1, 2015].

Gisler, M., Sornette, D. \& Woodard, R., 2011. Innovation as a social bubble: The example of the Human Genome Project. Research Policy, 40(10), pp.1412-1425.

Hyun Kim, J., 2012. A Hyperlink and Semantic Network Analysis of the Triple Helix (University-Government-Industry): The Interorganizational Communication Structure of Nanotechnology. Journal of Computer-Mediated Communication, 17(2), pp.152-170.

IDTechEx, 2012. IDTechEx forecasts a $\$ 100$ million graphene market in 2018. Cambridge Network.co.uk. Available at: https://www.cambridgenetwork.co.uk/news/idtechex-forecasts-a-100-milliongraphene-market-in-2018/ [Accessed March 20, 2012].

Jensen, E., 2012. Scientific Sensationalism in American and British Press Coverage of Therapeutic Cloning. Journalism E Mass Communication Quarterly, 89(1), pp.40-54.

Kinsley, S., 2012. Futures in the making: practices to anticipate "ubiquitous computing." Environment and Planning A, 44(7), pp.1554-1569.

Konrad, K. et al., 2012. Strategic responses to fuel cell hype and disappointment. Technological Forecasting and Social Change, 79(6), pp.1084-1098. 
Konrad, K. et al., 2017. The Future in STS: Performativity, Temporality and Anticipation. In C. A. Miller et al., eds. The Handbook of Science and Technology Studies, 4th edition. Cambridge, Massachusetts: MIT press, pp. 465-494.

Kozarsky, R., 2015. Case Closed: Graphene is the Next Carbon Nanotube. Lux Research Blog. Available at: http://blog.luxresearchinc.com/blog/2015/07/case-closedgraphene-is-the-next-carbon-nanotube/ [Accessed May 20, 2007].

te Kulve, H. et al., 2013. Context Matters: Promises and Concerns Regarding Nanotechnologies for Water and Food Applications. NanoEthics, 7(1), pp.17-27.

Law, J. \& Mol, A., 2002. Complexities: Social studies of knowledge practices, Durham and London: Duke University Press.

van Lente, H. et al., 1998. Expectations in Technological Developments: An Example of Prospective Structures to be Filled in by Agency. In Getting new technologies together: studies in making sociotechnical order. Berlin, pp. 203-230.

van Lente, H., Spitters, C. \& Peine, A., 2013. Comparing technological hype cycles: Towards a theory. Technological Forecasting and Social Change, 80(8), pp.1615-1628.

Master, Z. \& Resnik, D., 2013. Hype and Public Trust in Science. Science and Engineering Ethics, 19(2), pp.321-335.

Nerlich, B., 2013. Moderation impossible? On hype, honesty and trust in the context of modern academic life. The Sociological Review, 61, pp.43-57.

Peplow, M., 2013. Graphene: The quest for supercarbon. Nature, 503(7476), pp.327329.

Pollock, N. \& Williams, R., 2016. How industry analysts shape the digital future, Oxford: Oxford University Press. 
Pollock, N. \& Williams, R., 2010. The business of expectations: How promissory organizations shape technology and innovation. Social Studies of Science, 40(4), pp.525-548.

Pollock, N. \& Williams, R., 2015. The venues of high tech prediction: Presenting the future at industry analyst conferences. Information and Organization, 25(2), pp.115136.

Potstada, M. et al., 2016. An alignment approach for an industry in the making: DIGINOVA and the case of digital fabrication. Technological Forecasting and Social Change, 102, pp.182-192.

Ramiller, N.C., 2006. Hype! Toward a theory of exaggeration in information technology innovaton. . Academy of Management Proceedings, 2006(1), pp.A1-A6.

Reeves, P., 2014. The Econolyst's Dr Phil Reeves on embedding 3D Printing into the Supply Chain at TCT Show 2014.

Rinaldi, A., 2012. To hype, or not to(o) hype. EMBO Rep, 13(4), pp.303-307.

Rip, A., 2006. Folk Theories of Nanotechnologies. Science as Culture, 15(4), pp.349-365.

Ruef, A. \& Markard, J., 2010. What happens after a hype? How changing expectations affected innovation activities in the case of stationary fuel cells. Technological Analysis and Strategic Management, 22(3), pp.317-338.

Shapira, P., Youtie, J. \& Arora, S., 2012. Early patterns of commercial activity in graphene. Journal of Nanoparticle Research, 14(4), pp.1-15.

Steinert, M. \& Leifer, L., 2010. Scrutinizing Gartner's hype cycle approach. In Technology Management for Global Economic Growth (PICMET), 2010 Proceedings of PICMET'10:- pp. 1-13. 
Suddaby, R. \& Greenwood, R., 2001. Colonizing Knowledge: Commodification as a Dynamic of Jurisdictional Expansion in Professional Service Firms. Human Relations, 54(7), pp.933-953.

Swanson, E.B. \& Ramiller, N.C., 1997. The Organizing Vision in Information Systems Innovation. Organization Science, 8(5), pp.458-474.

TCT+Personalize, 2013. Nick Allen, Managing Director, 3DPRINTUK @ TCT Show + Personalize 2013.

Vasterman, P.L.M., 2005. Media-Hype: Self-Reinforcing News Waves, Journalistic Standards and the Construction of Social Problems. European Journal of Communication, 20(4), pp.508-530.

Wilkie, A. \& Michael, M., 2009. Expectation and Mobilisation. Science, Technology \& Human Values, 34(4), pp.502-522.

Wüstenhagen, R. et al., 2009. Financing fuel cell market development: exploring the role of expectation dynamics in venture capital investment. In S. Pogutz, A. Russo, \& P. Migliavacca, eds. Innovation, Markets, and Sustainable Energy: The Challenge of Hydrogen and Fuel Cells. Cheltenham, UK; Northampton, MA, USA, pp. 118-137. 